\title{
ASSESSMENT OF DIETARY EXPOSURE TO INORGANIC CHLORIDE, PHOSPHATE, AND SULPHATE BREAD ADDITIVES BY ION CHROMATOGRAPHY WITH CONDUCTOMETRIC DETECTION
}

\author{
M. BalcerzaK*, A. Rudnik and M. JelińsKa \\ Department of Analytical Chemistry, Faculty of Chemistry, \\ Warsaw University of Technology, Noakowskiego 3, 00-664 Warsaw. Poland
}

(Received: 19 May 2017; accepted: 30 May 2017)

\begin{abstract}
Bread is one of basic human dietary items. Bread products commercially available usually contain flour, water, yeast or sourdough, and numerous functional additives, among them inorganic chlorides (mainly $\mathrm{NaCl}$ ), phosphates, and sulphates, modifying physicochemical properties of final products to be attractive for consumers. Various kinds (whole-wheat, rye, and wheat rye) of Polish commercial breads were examined for contents of chlorides, phosphates, and sulphates by combination of water extraction and ion chromatography with conductometric detection. The evaluated amounts of the analytes corresponded to $0.58-1.06 \mathrm{~g}$ of chlorides (1-1.8 $\mathrm{g} \mathrm{NaCl}), 100-300 \mathrm{mg}$ of phosphates, and 10-130 mg of sulphates in $100 \mathrm{~g}$ (ca. two slices) of bread, which means that bread can be an important source of inorganic ions for humans, in particular in case of high consumption.
\end{abstract}

Keywords: food safety, bread, chlorides, phosphates, sulphates, ion chromatography

Bread is one of the most commonly consumed food products worldwide. Flour, water, yeast (Saccharomyces cerevisiae) or sourdough, and sodium chloride (salt) are the most significant ingredients for breads being produced at our times (MONDAL \& DATTA, 2008). Commercial breads usually contain a variety of additives, e.g. emulsifiers, anti-staling agents, sugar, malt, gums and hydrocolloids, enzymes, inorganic phosphates and sulphates, used during the production processes to obtain products of superior nutritional quality and attractive to consumers, in particular in flavour, texture, colour, and shelf life (OHIMAIN, 2015). Substrates used and baking conditions applied affect structural, physicochemical, and nutritive characteristics of final products (DEwetTinCK et al., 2008; Lopes AlmEIDA et al., 2016).

The amount of $\mathrm{NaCl}$ directly affects dough and bread properties (Miller \& Hoseney, 2008; Tuhumury et al., 2014). Sodium chloride acts as preservative agent and stabilizer of yeast fermentation rate. It enhances the flavour of the final product and increases dough mixing time. Slowing down the growth of moulds by salt is also known. Confirmed elevated intake of sodium chloride by consumers, approximately $8-11 \mathrm{~g} /$ day by European population, as compared with dietary needs (3-4 g/day in adults) (EFSA, 2005; LYNCH et al., 2009) requires monitoring of its sources in human diet. Bread products are responsible for about $20-25 \%$ of daily sodium chloride intake. The content of salt in breads from some European countries (Portugal, Spain, France, UK, and Turkey) ranged from 1.01\% (UK) to $1.82 \%$ (Turkey) (mean values) within the period of 2006-2009 (Quilez \& SALAS-SALvAdo, 2012). A reduction of the amount of salt used for the preparation of home-made food and its content in industrial food products is recommended by health authorities worldwide (IOM, 2005;

\footnotetext{
* To whom correspondence should be addressed. Phone: +48 22 2345104; e-mail: mbal@ch.pw.edu.pl
} 
EFSA, 2005; He \& MACGregor, 2010; Kloss et al., 2015). Legal regulations on maximum limit of sodium chloride for bread products were introduced in some countries, e.g. $1.4 \mathrm{~g}$ $\mathrm{NaCl}$ per $100 \mathrm{~g}$ of bread in Portugal (Placido et al., 2012).

The amount of sodium chloride in breads can be evaluated through the quantification of either chloride or sodium and converting their contents into the corresponding $\mathrm{NaCl}$ (PLACIDO et al., 2012; CAPUANo et al., 2013). Potentiometric (ISE) method is most widely applied for the evaluation of chloride content in various food products. Atomic absorption spectrometry is commonly used for the determination of sodium. Significant differences, however, were reported in calculated total amounts of $\mathrm{NaCl}$ when using the results obtained for chloride or sodium contents for various food products determined by those techniques. Ion chromatography offers the possibility of the isolation of the analyte signal from the other sample components, which results in substantially better selectivity as compared with the other techniques.

Phosphorus food additives are used to extend conservation, enhance colour or flavour, and retain moisture in a large number of foodstuffs. In bakery industry, phosphorus additives are also used as leavening agents, fluffing up the texture of final products as a result of the reaction of phosphates with sodium bicarbonate and releasing of carbon dioxide. Phosphorus food additives permitted in the European Union include phosphoric acid (E 338) and inorganic phosphate, di-, tri- and polyphosphate salts (E 339-452) (EC, 2011; EFSA, 2013). Added phosphates are almost completely (approaching 100\%) absorbed in the intestine contrary to those of natural origin. The evaluation of phosphorus load from food additives is an urgent problem taking into consideration data on the increase in phosphorus intake, e.g. from 470 $\mathrm{mg} /$ day to $1000 \mathrm{mg} /$ day within the period 1990s-2000s (American diet) (KARALIS \& MurPHYGuteKUnst, 2006). A high serum phosphate concentration has been considered a major risk factor of cardiovascular disease and mortality in general population, in particular in patients with chronic kidney disease (CKD) and those under dialysis (BENINI et al., 2011; D'AlessANDro et al., 2015). Limited data on the content of inorganic phosphate anions in breads are available (Ritz et al., 2012; SHERIDAN, 2012). For white and whole-wheat bread the amount of phosphate in the range of 50-200 $\mathrm{mg}$ in $100 \mathrm{~g}$ samples was found (RITZ et al., 2012).

UV-vis spectrophotometry, based on the formation of phosphomolybdate or phosphomolybdenum blue, is most commonly used for the determination of orthophosphates in a large variety of food samples (MARCZENKO \& BALCERZAK, 2007). The necessity of careful optimization of experimental conditions that largely influence the formation of phosphomolybdate and interfering effects from $\mathrm{As}(\mathrm{V}), \mathrm{Si}$, and Ge giving heteropolyacids, are disadvantages of spectrophotometric methods. The interest in the applications of other instrumental techniques of better selectivity and detection limits (DLs) for the detection of phosphates in complex materials is growing.

Bread fortification with sulphate salts of some microelements, e.g. iron and zinc (AHMED et al., 2012), is a source of sulphates for consumers. Adverse effects (osmotic diarrhoea) can occur in case of high intake of inorganic sulphates. Till now, no direct recommendations for inorganic sulphate, both adequate or a tolerable upper intake, were established due to still insufficient data. Gravimetric, turbidimetric, colorimetric, and ion chromatographic methods are of interest for determining sulphates in complex samples (KARMARKAR \& TABATABAI, 2000). Ion chromatography is best due to its higher selectivity and sensitivity compared to the other methods (WEISS, 2004; MiCHALSKI, 2010). 


\section{Materials and methods}

\subsection{Materials}

Three different kinds of bread, wholemeal, rye, and wheat rye, each from four different producers, available on the local market, were examined.

\subsection{Methods}

Ion chromatography (IC) with conductometric detection was applied for simultaneous determination of the analytes in the aqueous extracts of the examined samples.

\subsection{Instrumentations}

The 883 Basic IC Compact System from Metrohm AG (Herisau, Switzerland), consisting of a MSM II (Metrohm Suppressor Module) suppressor and conductometric detector, was used. Anions separation was carried out on the Metrosep A Supp $4(250 \mathrm{~mm} \times 4 \mathrm{~mm})$ column with Metrosep A Supp 4/5 Guard column, both from Metrohm. For sample preparation, Hettich Universal 320 Centrifuge, (Germany) and filters of pore size of $0.45 \mu \mathrm{m}$ MCE (Fisherbrand) as well as sample preparation cartridge IC-RP (C18) from Metrohm were applied.

The volume of a sample injection loop was $20 \mu \mathrm{l}$. The MagIC Net 2.3 (Metrohm) software was used for data acquisition and evaluation of chromatograms.

\subsection{Chemicals and standards}

Standard solutions of chloride, orthophosphate, sulphate, bromide, fluoride, nitrate(III) and nitrate $(\mathrm{V})$, and oxalate anions prepared from high purity sodium salts and oxalic acid (from Fluka) and containing $1000 \pm 4 \mathrm{mg} \mathrm{l}^{-1}$ of each anion, were used.

Sodium carbonate $\left(\mathrm{Na}_{2} \mathrm{CO}_{3}\right)$ and sodium bicarbonate $\left(\mathrm{NaHCO}_{3}\right)$ from Fluka were used for the preparation of the eluent: $1.8 \mathrm{mmol} \mathrm{l}^{-1} \mathrm{Na}_{2} \mathrm{CO}_{3}+1.7 \mathrm{mmol} \mathrm{l}^{-1} \mathrm{NaHCO}_{3}(\mathrm{pH} \mathrm{10.2)}$.

Deionized water obtained from a Millipore Elix3/Simplicity system (resistivity $\left.18.2 \mathrm{M} \Omega \mathrm{cm}\left(25^{\circ} \mathrm{C}\right)\right)$ was used in all experiments.

\section{Results and discussion}

\subsection{Calibration procedure}

Four synthetic mixtures, containing the desired anions at concentrations in the ranges of 0.8-75.0 $\left(\mathrm{Cl}^{-}\right), 0.8-50.0\left(\mathrm{PO}_{4}{ }^{3-}\right)$ and 1.0-50.0 $\left(\mathrm{SO}_{4}{ }^{2-}\right) \mathrm{mg} \mathrm{l^{-1 }}$, were used for the instrument calibration. Additional inorganic $\left(\mathrm{F}^{-}, \mathrm{NO}_{2}^{-}, \mathrm{NO}_{3}^{-}\right.$, and $\left.\mathrm{Br}\right)$ and oxalate $\left(\mathrm{C}_{2} \mathrm{O}_{4}{ }^{2-}\right)$ anions were introduced into calibration solutions, because their signals were simultaneously registered with those of analytes under chromatographic conditions used. Selective isolation of the signals of the analytes from the mixture with other ionic species that can occur in the examined complex samples is fundamental for their identification and quantitation. Figure 1 presents the chromatograms of the synthetic mixtures of the anions examined. Detection limits of chloride, phosphate, and sulphate anions were determined following the analysis of their synthetic mixtures, where minimum concentrations detected were $0.4\left(\mathrm{Cl}^{-}\right), 0.4\left(\mathrm{PO}_{4}^{3-}\right)$, and $0.5\left(\mathrm{SO}_{4}^{2-}\right) \mathrm{mg} \mathrm{l}^{-1}$, and calculated as triple standard deviations $(\mathrm{SD})$ of the results $(\mathrm{n}=6)$. The values of DLs were as follows: $0.01\left(\mathrm{Cl}^{-}\right), 0.05\left(\mathrm{PO}_{4}^{3-}\right)$, and $0.03\left(\mathrm{SO}_{4}{ }^{2-}\right) \mathrm{mg} \mathrm{l}^{-1}$. 


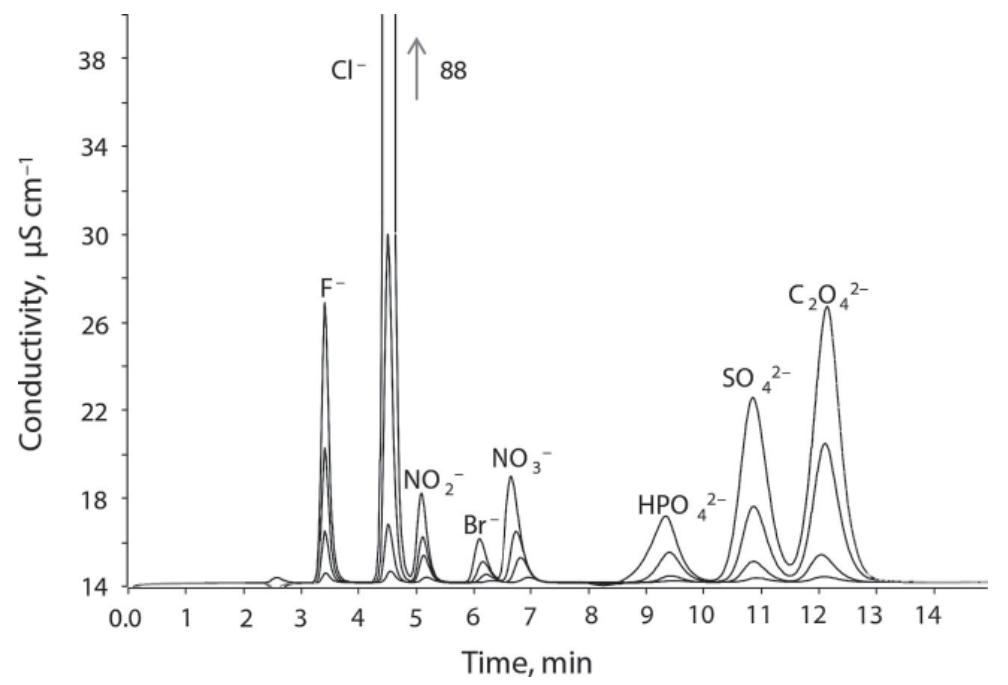

Fig. 1. Chromatograms of synthetic mixtures of ions $\mathrm{F}^{-}(0.4-10.0), \mathrm{Cl}^{-}(0.8-75.0), \mathrm{NO}_{2}^{-}(0.4-10.0), \mathrm{Br}^{-}(0.4-$ 10.0), $\mathrm{NO}_{3}^{-}(1.0-20.0), \mathrm{HPO}_{4}^{2-}(0.8-50.0), \mathrm{SO}_{4}^{2-}(1.0-50.0)$, and $\mathrm{C}_{2} \mathrm{O}_{4}^{2-}(2.0-100.0) \mathrm{mg} \mathrm{l}^{-1}$ (Metrosep A Supp 4 column, $1.8 \mathrm{mmol} \mathrm{l}^{-1} \mathrm{Na}_{2} \mathrm{CO}_{3}+1.7 \mathrm{mmol} \mathrm{l}^{-1} \mathrm{NaHCO}_{3}\left(1 \mathrm{ml} \mathrm{min}^{-1}\right)$ eluent $)$

\subsection{Analysis of bread samples}

Chromatographic procedure described above was applied for the determination of chloride, phosphate, and sulphate ions extracted with water from the examined bread samples. The samples were taken from the exterior parts (without crusts) of two slices of bread preliminary homogenized. The samples of about $2-5 \mathrm{~g}$ were treated with $250 \mathrm{ml}$ of deionized water for $15 \mathrm{~min}$ to extract chloride, phosphate, and sulphate ions. These ratio of extractant volume to sample mass and extraction time applied provided the highest recovery of the anions from the examined samples. A part of each sample was transferred into 50-ml Falcon tube and centrifuged (4000 r.p.m. for $15 \mathrm{~min}$ ). The upper aqueous layer was filtered using $0.45-\mu \mathrm{m}$ membrane filter and IC-RP cartridge (for removing of any soluble organic matrix components) before injection into the chromatographic column.

Three independent analyses were carried out for particular breads examined and triplicate analyses of each extracts were performed. Figure 2 shows the examples of chromatograms of the examined breads, wholewheat (wholemeal) (Fig. 2A), rye (Fig. 2B), and wheat rye (Fig. 2C). The evaluated contents of particular anions in the examined commercial breads are given in Table 1 . The accuracy of the procedure applied was evaluated by a standard addition method. Spike solution containing $2 \mathrm{mg} \mathrm{Cl}^{-}, 2.5 \mathrm{mg} \mathrm{PO}_{4}^{3-}$, and $5 \mathrm{mg}$ $\mathrm{SO}_{4}^{2-}$ ions was introduced into the examined sample prior to the extraction step. The recoveries of the anions were in the range of $96-99 \%$. 
A

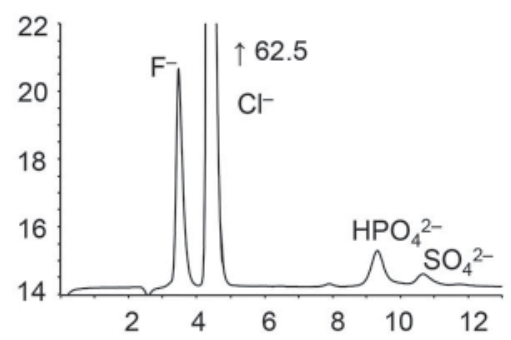

B

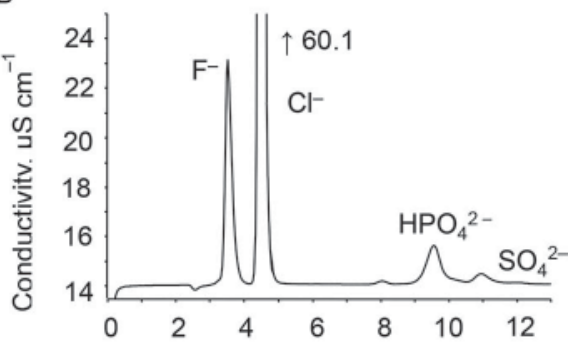

C

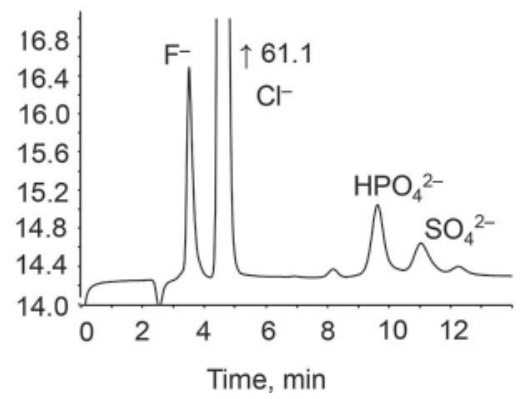

Fig. 2. Ion chromatograms of (A) wholemeal, (B) rye, and (C) wheat rye breads

Table 1. The amounts of chloride, phosphate, and sulphate ions in breads $(\mathrm{n}=3)$

\begin{tabular}{lccc}
\hline A kind of bread & \multicolumn{3}{c}{ Anions, $\mathrm{x} \pm \mathrm{SD}, \mathrm{mg} \mathrm{g}^{-1}$} \\
\cline { 2 - 4 } & $\mathrm{Cl}^{-}$ & $\mathrm{PO}_{4}^{3-}$ & $\mathrm{SO}_{4}^{2-}$ \\
\hline \multirow{3}{*}{ Wholemeal } & $7.16 \pm 0.07$ & $2.00 \pm 0.04$ & $0.35 \pm 0.01$ \\
& $6.69 \pm 0.04$ & $2.99 \pm 0.02$ & $0.37 \pm 0.01$ \\
& $5.83 \pm 0.77$ & $2.26 \pm 0.05$ & $1.30 \pm 0.59$ \\
& $10.61 \pm 0.65$ & $2.97 \pm 0.14$ & $0.33 \pm 0.05$ \\
\hline \multirow{3}{*}{ Rye } & $5.88 \pm 0.05$ & $1.20 \pm 0.02$ & $0.31 \pm 0.01$ \\
& $7.19 \pm 0.20$ & $0.75 \pm 0.02$ & $0.12 \pm 0.01$ \\
& $6.08 \pm 0.07$ & $1.44 \pm 0.05$ & $0.32 \pm 0.08$ \\
Wheat rye bread & $9.38 \pm 0.16$ & $1.23 \pm 0.06$ & $0.12 \pm 0.01$ \\
\hline & $7.90 \pm 0.05$ & $0.81 \pm 0.02$ & $0.21 \pm 0.08$ \\
& $7.81 \pm 0.06$ & $1.05 \pm 0.06$ & $0.17 \pm 0.01$ \\
& $5.80 \pm 0.08$ & $1.19 \pm 0.08$ & $0.29 \pm 0.64$ \\
& $8.82 \pm 0.13$ & $1.22 \pm 0.05$ & $0.19 \pm 0.01$ \\
\hline
\end{tabular}


The chloride contents in the examined breads were in the range of 5.8-10.6 $\mathrm{mg} \mathrm{g}^{-1}$ with no significant differences between commercial products. Such amounts correspond to about 1-1.8 g NaCl consumed with $100 \mathrm{~g}$ (ca. two slices) of bread. Higher amounts of soluble phosphates, in the range of $2-3 \mathrm{mg} \mathrm{g}^{-1}$, were determined in wholemeal products compared with rye $\left(0.75-1.4 \mathrm{mg} \mathrm{g}^{-1}\right)$ and wheat rye $\left(0.8-1.2 \mathrm{mg} \mathrm{g}^{-1}\right)$ breads. Two slices of bread can be source of about 100-300 mg of phosphates consumed. The determined amounts of sulphate anions in the examined extracts were in the range of $0.1-1.3 \mathrm{mg} \mathrm{g}^{-1}(10-130 \mathrm{mg}$ in $100 \mathrm{~g}$ portion) and do not significantly differ in different breads. It can be stated that the amounts of particular anions that enter the human body can increase with higher bread consumption.

\section{Conclusions}

Bakery products are among the sources providing inorganic chlorides, phosphates, and sulphates in human diet as the result of their use as functional additives in the production process. The evaluated amounts of chlorides, phosphates, and sulphates in commercial Polish breads examined in this work corresponded to $1-1.8 \mathrm{~g} \mathrm{NaCl}, 100-300 \mathrm{mg}$ of phosphates, and $10-130 \mathrm{mg}$ of sulphates in $100 \mathrm{~g}$ (ca. two slices of bread). Higher bread consumption results in higher amounts of particular anions entering the human body. Ion chromatography is an attractive method for direct and rapid simultaneous determination of inorganic ionic species extracted from the examined samples.

Financial support of the work by the Warsaw University of Technology is kindly acknowledged.

\section{References}

D’Alessandro, C., Piccoli, G.B. \& Cupisti, A. (2015): The “phosphorus pyramid”: a visual tool for dietary phosphate management in dialysis and CKD patients. BMC Nephrol., 16(9), doi: 10.1186/1471-2369-16-9

Ahmed, A., Anjum, F.M., Randhawa, M.A., Farooq, U., Akhtar, S. \& Sultan, M.T. (2012): Effect of multiple fortification on the bioavailability of minerals in wheat meal bread. J. Food Sci. Tech., 49, 737-744.

Benini, O., D’Alessandro, C., Gianfaldoni, D. \& Cupisti, A. (2011): Extra-phosphate load from food additives in commonly eaten foods: a real and insidious danger for renal patients. J. Renal Nutr., 21, 303-308.

Capuano, E., Van Der Veer, G., Verheijen, P.J.J., Heenan, S.P., Van De Laak, L.F.J., Koopmans, H.B.M. \& Van Ruth, S.M. (2013): Comparison of a sodium-based and a chloride-based approach for the determination of sodium chloride content of processed foods in the Netherlands. J. Food Comp. Anal., 31, 129-136.

Dewettinck, K., Van Bockstaele, F., Kühne, B., Van De Walle, D., Courtens, T.M. \& Gellynck, X. (2008): Nutritional value of bread: Influence of processing, food interaction and consumer perception. J. Cereal Sci., 48, 243-257.

EC (2011): Regulation No 1129/2011 of the European Parliament and of the Council of 11 November 2011 amending Annex II to Regulation (EC) No 1333/2008 of the European Parliament and of the Council by establishing a Union list of food additives. OJ L 295, 12.11.2011, 1-177.

EFSA (2005): Opinion of the scientific panel on dietetic products, nutrition and allergies on a request from the Commission related to the tolerable upper intake level of chloride (Request $\mathrm{N}^{\circ}$ EFSA-Q-2003-018). EFSA J. 210, 1-9.

EFSA (2013): Assessment of one published review on health risks associated with phosphate additives in food. Statement of EFSA. EFSA J., 11, 3444, 1-27.

He, F.J. \& MacGregor, G.A. (2010): Reducing population salt intake worldwide: From evidence to implementation. Prog. Cardiovasc. Dis., 52, 363-382. 
IOM (2005): Dietary reference intakes for water, potassium, sodium, chloride, and sulfate. Institute of Medicine. The National Academic Press, Washington, DC. 617 pages.

Karalis, M. \& Murphy-Gutekunst, L. (2006): Patient education: enhanced foods - hidden phosphorus and sodium in foods commonly eaten. J. Ren. Nutr., 16, 79-81.

Karmarkar, S.V. \& Tabatabai, M.A. (2000): Sulfate, sulphite, and sulphide. -in: Nollet L.M.L. (Ed.), Handbook of water analysis. Marcel Dekker, USA. pp. 195-199.

Kloss, L., Dawn Meyer, J., Graeve, L. \& Vetter, W. (2015): Sodium intake and its reduction by food reformulation in the European Union - A review. NFS J., 1, 9-19.

Lopes Almeida, E., Steel, C.J. \& Chang, Y.K. (2016): Par-baked bread technology: formulation and process studies to improve quality. Crit. Rev. Food Sci. Nutr., 56, 70-81.

Lynch, E.J., Dal Bello, F., Sheehan, E.M., Cashman, K.D. \& Arendt, E.K. (2009): Fundamental studies on the reduction of salt on dough and bread characteristics. Food Res. Int., 42, 885-891.

MarczenKo, Z. \& BALCERZAK, M. (2007): Методы спектрофотометрии в УФ и видимой областях в неорганическом анализе (UV-Vis spectrophotometric methods in inorganic analysis). Binom, Moscow, 711 pages.

Michalski, R. (2010): Food analysis: Ion chromatography. -in: CAZES, J. (Ed.) Encyclopedia of chromatography Taylor \& Francis, CRC Press, Boca Raton, FL. USA. pp. 909-912.

Miller, R.A. \& Hoseney, R.C. (2008): Role of salt in baking. Cereal Food World, 53, 4-6.

Mondal, A. \& DatTA, A.K. (2008): Bread baking - A review. J. Food Eng., 86, 465-474.

Ohimain, E.I. (2015): Recent advances in the production of partially substituted wheat and wheatless bread. Eur. Food Res. Technol., 240, 257-271.

Placido, A., Kupers, R., Paiga, P., Magalhaes, J., Nouws, H.P., Delerue-Matos, C. \& Oliveira, M.B.P. (2012): Salt content in bread and dough from northern Portugal: Method development and comparison. J. Food Comp. Anal., 27, 14-20.

Quilez, J. \& Salas-Salvado, J. (2012): Salt in bread in Europe: potential benefits of reduction. Nutr. Rev., 70, 666678.

Ritz, E., Hahn, K., Ketteler, M., Kuhlmann, M.K. \& Mann, J. (2012): Phosphate additives in food - a health risk. Dtsch. Arztebl. Int., 109, 49-55.

SHERIDAN, K. (2012): Choosing a bread that will fit the chronic kidney disease diet: an emphasis on sodium and phosphorus. J. Renal Nutr., 22, e27-e35.

Tuhumury, H.C.D., Small, D.M. \& Day, L. (2014): The effect of sodium chloride on gluten network formation and rheology. J. Cereal Sci., 60, 229-237.

WeIss, J. (2004): Handbook of ion chromatography. Wiley-VCH: Weinheim. 894 pages. 